University of Wollongong

Research Online

Faculty of Engineering and Information

Faculty of Engineering and Information

Sciences - Papers: Part A

Sciences

$1-1-2014$

Ozonation of $\mathrm{N}$-nitrosamines in the reverse osmosis concentrate from water recycling applications

Takahiro Fujioka

University of Wollongong, takahiro@uow.edu.au

Stuart Khan

University of New South Wales, s.khan@unsw.edu.au

James McDonald

University of New South Wales

Long Nghiem

University of Wollongong, longn@uow.edu.au

Follow this and additional works at: https://ro.uow.edu.au/eispapers

Part of the Engineering Commons, and the Science and Technology Studies Commons

Research Online is the open access institutional repository for the University of Wollongong. For further information contact the UOW Library: research-pubs@uow.edu.au 


\title{
Ozonation of $\mathrm{N}$-nitrosamines in the reverse osmosis concentrate from water recycling applications
}

\begin{abstract}
This study aims to evaluate the performance of ozone treatment for removing $\mathrm{N}$-nitrosamines from reverse osmosis (RO) concentrate in water recycling applications. In the absence of any N-nitrosamine precursors, the destruction efficiency of $\mathrm{N}$-nitrosamines was dependent on their molecular weight or the length of the alkyl chain in their molecular structure. Experiments conducted with RO concentrate showed that ozonation could lead to the formation of $\mathrm{N}$-nitrosodimethylamine (NDMA) and N-nitrosodiethylamine (NDEA), resulting in an increase in concentrations of these $\mathrm{N}$-nitrosamines. Nevertheless, ozonation was effective for destruction of N-nitrosamines with molecular weight greater than that of NDEA (102 $\mathrm{g} / \mathrm{mol})$. 2014 Copyright 2014 International Ozone Association.
\end{abstract}

\section{Keywords}

osmosis, concentrate, water, recycling, ozonation, applications, n, nitrosamines, reverse

\section{Disciplines}

Engineering | Science and Technology Studies

\section{Publication Details}

Fujioka, T., Khan, S. J., McDonald, J. A. \& Nghiem, L. D. (2014). Ozonation of N-nitrosamines in the reverse osmosis concentrate from water recycling applications. Ozone: Science and Engineering, 36 (2), 174-180. 


\title{
Ozonation of N-nitrosamines in the Reverse Osmosis Concentrate from Water Recycling Applications
}

(Shortened version: Ozonation of N-nitrosamines in RO concentrate)

\author{
Revised manuscript Submitted to \\ Ozone: Science \& Engineering
}

October 2013

Takahiro Fujioka ${ }^{1,}$, Stuart J. Khan ${ }^{2}$, James A. McDonald ${ }^{2}$, Long D. Nghiem ${ }^{1}$

${ }^{1}$ Strategic Water Infrastructure Laboratory, School of Civil Mining and Environmental

Engineering, The University of Wollongong, NSW 2522, Australia

${ }^{2}$ UNSW Water Research Centre, School of Civil and Environmental Engineering, The University of New South Wales, NSW 2052, Australia

* Corresponding author: Takahiro Fujioka, Email: tf385@uowmail.edu.au, Ph +61 424279164 


\begin{abstract}
This study aims to evaluate the performance of ozone treatment for removing N-nitrosamines from reverse osmosis (RO) concentrate in water recycling applications. In the absence of any $\mathrm{N}$-nitrosamine precursors, the destruction efficiency of N-nitrosamines was dependent on their molecular weight or the length of the alkyl chain in their molecular structure. Experiments conducted with RO concentrate showed that ozonation could lead to the formation of Nnitrosodimethylamine (NDMA) and N-nitrosodiethylamine (NDEA), resulting in an increase in concentrations of these N-nitrosamines. Nevertheless, ozonation was effective for destruction of N-nitrosamines with molecular weight greater than that of NDEA $(102 \mathrm{~g} / \mathrm{mol})$.
\end{abstract}

Keywords: Ozone; N-nitrosamines; N-nitrosodimethylamine (NDMA); Reverse osmosis concentrate; Trace organic chemicals; Water reuse. 


\section{Introduction}

The occurrence of trace organic chemicals (TrOCs) in wastewater and reclaimed effluent has attracted significant attention in recent years due to their potential adverse impacts to public health and the environment. A diverse range of TrOCs can be identified in treated effluent generally at part per trillion $(\mathrm{ng} / \mathrm{L})$ to billion levels $(\mu \mathrm{g} / \mathrm{L})$. In a typical water recycling intended for potable water reuse, these TrOCs are removed through a series of wastewater treatment processes which include reverse osmosis (RO) filtration treatment. In such indirect potable water reuse scheme, the RO filtration process is used to remove salinity and to ensure the removal TrOCs (Shannon et al. 2008, Bellona et al. 2004). Water recovery of the RO filtration process deployed for water recycling applications can be up to $85 \%$ (Fujioka et al. 2012). Thus, TrOCs can accumulate in the final $\mathrm{RO}$ concentrate (or brine) by up to eight times in comparison to the feed (Benner et al. 2008). The accumulation of TrOCs in the RO concentrate presents a major challenge for implementation of inland water recycling schemes because RO concentrate disposal can be subject to environmental regulation.

A group of TrOCs that have become a significant concern in water recycling applications is $\mathrm{N}$ nitrosamines due to their potential carcinogenic properties (USEPA 1993). Nnitrosodimethylamine (NDMA) is probably the most studied N-nitrosamine compound in water reuse applications, due to its frequent occurrence in RO feed water. These N-nitrosamines are known to occur as by-products during the disinfection of secondary treated effluent. In a RObased water recycling application, chloramines are added to the secondary treated effluent prior to the RO process to protect the membrane from biofouling. Chloramines can react with nitrogen 
bearing compounds to form NDMA and possibly other N-nitrosamines (Mitch et al. 2003). Some $\mathrm{N}$-nitrosamines can also be formed during industrial activities such as rubber production. Thus, NDMA has been frequently detected at 20-200 ng/L in RO feed of waters (Plumlee et al. 2008, Farré et al. 2011a, Fujioka et al. 2013b). In addition to NDMA, several other N-nitrosamines including N-nitrosomethylethylamine $\quad$ (NMEA), N-nitrosopyrrolidine $\quad$ (NPYR), Nnitrosodiethylamine (NDEA), N-nitrosopiperidine (NPIP), N-nitrosomorpholine (NMOR), Nnitrosodipropylamine (NDPA), and N-nitrosodi-n-butylamine (NDBA) have also been reported in wastewater and secondary treated effluent (Krauss et al. 2010, Reyes-Contreras et al. 2012). In particular, NMOR has been detected at high concentrations $(>1 \mu \mathrm{g} / \mathrm{L})$ in several cases in secondary treated effluent (Krasner et al. 2009, Fujioka et al. 2013a). NDMA is partially rejected by RO membranes. Rejections of other N-nitrosamines by RO membranes can be significantly considerably higher. Fujioka (Fujioka et al. 2013b) conducted a full-scale study and reported that $\mathrm{N}$-nitrosamine concentrations in the final RO concentrate could up to six times higher than those in the RO feed.

Further development of inland water recycling schemes necessitates the development of suitable technologies for the treatment of RO concentrate. Among several advanced water treatment technologies for RO concentrate treatment reviewed by Pérez-González (2012), ozonation has been identified as promising approach for the removal of TrOCs (Reungoat et al. 2010, Lee et al. 2012). Both ozone and the hydroxyl radical, which forms during ozone decomposition in aqueous solution, are strong oxidants. Previous research has demonstrated that ozonation can effectively oxidise a wide range of TrOCs, particularly those contain olefin, amine or aromatic functional groups in their molecular structure (Snyder et al. 2006, Lee et al. 2007). However, 
little is known about the effectiveness of ozonation for the removal of N-nitrosamines. Pisarenko et al. (2012) reported $12 \%$ removal of NDMA by ozonation in a river water at $10 \mathrm{mg} / \mathrm{L}$ ozone dosage. NDMA has previously been shown to be oxidised by hydroxyl radical (Landsman et al. 2007) and is converted into methylamine via several pathways (Lee et al. 2007). Ozonation can also lead to the formation of NDMA, as a result of oxidation of NDMA precursors, including dimethylamine (DMA), that are abundant in wastewater (Andrzejewski and Nawrocki 2009, Andrzejewski et al. 2008). In addition to DMA, several other NDMA precursors such as $\mathrm{N}, \mathrm{N}$ dimethylsulfamide and some pharmaceuticals have been reported to form NDMA during ozonation (Farré et al. 2011b, Schmidt and Brauch 2008, Bond et al. 2011). It is also noteworthy that the fate of the other N-nitrosamines during ozonation has been scarcely investigated. To the best of our knowledge, no studies have previously reported the ozonation of RO concentrates to examine possible $\mathrm{N}$-nitrosamine formation and/or destruction.

The aim of this study was to provide an understanding of the effect of ozone oxidation on $\mathrm{N}$ nitrosamines in RO concentrate. Ozonation of eight N-nitrosamines was first conducted in an aqueous matrix that does not contain any other organic matter to evaluate the effectiveness of ozonation on N-nitrosamine destruction. RO concentrate collected from a full-scale RO plant was then used to examine the impact of N-nitrosamine precursors during ozonation.

\section{Materials and methods}

\section{Chemicals}

Analytical grade N-nitrosamines (Table 1) were purchased from Sigma-Aldrich (Castle Hill, NSW, Australia). A stock solution containing $10 \mathrm{mg} / \mathrm{L}$ of each N-nitrosamine was prepared in 
pure methanol. Deuterated N-nitrosamines (N-nitrosodimethylamine-D6, Nnitrosomethylethylamine-D3, N-nitrosopyrrolidine-D8, N-nitrosodiethylamine-D10, Nnitrosopiperidine-D10, N-nitrosomorpholine-D8, N-nitrosodipropylamine-D14 and N-nitrosodin-butylamine-D9) were obtained from CDN isotopes (Pointe-Claire, Quebec, Canada). A stock solution containing $100 \mu \mathrm{g} / \mathrm{L}$ of each deuterated N-nitrosamine was also prepared in pure methanol. All stock solutions were kept at $-18{ }^{\circ} \mathrm{C}$ in the dark and used within one month of preparation. Analytical grade $\mathrm{NaCl}, \mathrm{CaCl}_{2}$ and $\mathrm{NaHCO}_{3}$ were from Ajax Finechem (Taren Point, NSW, Australia).

A synthetic solution containing $250 \mathrm{ng} / \mathrm{L}$ of each N-nitrosamine, $20 \mathrm{mM} \mathrm{NaCl}, 1 \mathrm{mM} \mathrm{NaHCO}$ and $1 \mathrm{mM} \mathrm{CaCl} 2$ was prepared from Milli-Q water to evaluate the effectiveness of ozonation on N-nitrosamine destruction without any interference from other organic substances. Similar synthetic feed solutions have been applied by other researchers (Ang et al. 2011, Jermann et al. 2009). In addition, RO concentrate was collected from a water recycling plant in Australia. The treatment processes used in this plant consisted of conventional wastewater treatment, sand filtration, microfiltration, and $\mathrm{RO}$ filtration. The $\mathrm{RO}$ filtration system was operated at $85 \%$ water recovery and RO concentrate was collected from the third (final) stage. Because some Nnitrosamines were not identified in the raw RO concentrate, $\mathrm{N}$-nitrosamines were dosed at 250 $\mathrm{ng} / \mathrm{L}$ of each N-nitrosamine. N-nitrosamines were introduced to the test solution in a methanol matrix, nevertheless, the presence of methanol did not significantly interfere with their destruction by ozonation. A preliminary ozone treatment experiment in the synthetic solution with an ozone dosage of $45 \mathrm{mg} / \mathrm{L}$ exhibited less $15 \%$ methanol removal (measured as total organic carbon concentration). Our results are also consistent with a previous study by Alborzfar 
et al. (2000) who reported that the presence of methanol only had a negligible impact on the removal of 3,4-dichlorobut-1-ene from an aqueous solution by ozonation and that reaction rate constant between ozone and methanol was insignificant.

\section{[Table 1]}

\section{Ozonation system and experimental protocols}

The ozonation system used in this investigation (Figure 1) comprised an ozone generator (CD10/AD, ClearWater Tech, USA), a gas flow meter, a glass ozone reactor and a gas phase ozone concentration analyser (ME820, Ebara Jitsugyo, Japan). The ozone generator can produce up to $1.3 \mathrm{~g}$ of ozone per hour. Instrumental grade air was used for the ozone generation. The gas phase ozone concentration monitor is an ultraviolet (UV) meter which is often used for the measurement of ozone concentration in gas phase (Rakness et al. 1996).

At the beginning of each experiment, the by-pass valve shown in Figure 1 was opened and the amount of generated ozone was first determined using the ozone analyser. The generated ozone concentration $\left(C_{i n}\left[\mathrm{~g} / \mathrm{Nm}^{3}\right]\right)$ was set at $20 \mathrm{~g} / \mathrm{Nm}^{3}$ by adjusting the power volume of the ozone generator. Normal reference conditions (one atmospheric pressure and $0{ }^{\circ} \mathrm{C}$ ) were used for ozone measurement (Rakness et al. 1996). The gas flow rate $\left(G\left[\mathrm{Nm}^{3} / \mathrm{min}\right]\right)$ was set at a constant value so that the amount of ozone generated, as expressed by $C_{i n} \times G$, was maintained constant. Then ozonation experiments were initiated by closing the bypass valve and transferring the ozone gas into the ozone reactor. The volume of sample in the ozone reactor $(V[\mathrm{~L}])$ was $2 \mathrm{~L}$. During the experiments, the off-gas ozone concentration at ozonation time $t[\mathrm{~min}]\left(C_{\text {out }}(t)\left[\mathrm{g} / \mathrm{Nm}^{3}\right]\right)$ was monitored using the ozone concentration analyser. Ozone dose was continued until the target 
ozone dosage (i.e. 15,30 or $45 \mathrm{mg} / \mathrm{L})$ was achieved. Overall ozone dosage into a solution ( $D_{O 3}$ $(t)[\mathrm{mg} / \mathrm{L}])$ can be calculated as follows:

[1] $D_{O 3}(t)=\int_{0}^{t} \frac{G\left[C_{\text {in }}-C_{\text {out }}(t)\right] d t}{V}$

Following the completion of the ozone dose, the ozonated solution samples were maintained in the reactor for at least 20 minutes to complete ozone reactions with dissolved ozone. Thereafter, duplicate samples $(200 \mathrm{~mL})$ were collected in amber glass bottles.

\section{[Figure 1]}

\section{Analytical technique}

The concentrations of $\mathrm{N}$-nitrosamines were determined using an analytical method previously reported by McDonald et al. (2012). The method includes solid phase extraction (SPE), followed by gas chromatography and analysis by tandem mass spectrometry with electron impact ionization. The $\mathrm{N}$-nitrosamine surrogate stock solution was added to each sample bottle to obtain $50 \mathrm{ng}$ of each isotope labelled N-nitrosamine. SPE was then carried out using Supelclean ${ }^{\mathrm{TM}}$ Coconut Charcoal SPE cartridges (Supelco, St Louis, MO, USA). The concentrations of Nnitrosamines were quantified using an Agilent 7890A gas chromatograph coupled with an Agilent 7000B triple quadrupole mass spectrometer. The quantitative detection limits determined with this analytical technique are $3 \mathrm{ng} / \mathrm{L}$ for NDMA, NDEA, NPIP and NMOR and $5 \mathrm{ng} / \mathrm{L}$ for NMEA, NPYR, NDPA and NDBA. 
Conductivity and $\mathrm{pH}$ were measured using an Orion 4-Star Plus $\mathrm{pH} /$ conductivity meter (Thermo Scientific, USA). $\mathrm{UV}_{254}$ and $\mathrm{UV}_{400}$ absorbance were analysed using a UV-1700 spectrophotometer (Shimadzu, Japan). Total organic carbon (TOC) concentrations were determined using a TOC-VCSH analyser (Shimadzu, Japan). Cations were analysed using an Inductive Coupled Plasma-Mass Spectrometer (7500CS, Agilent Technologies, Wilmington, DE, USA). Anions were analysed by an ion chromatography system (Shimadzu, Tokyo, Japan).

\section{Results and discussion}

\section{Synthetic solution}

The eight N-nitrosamines investigated here observed to be transformed by ozonation to some extent. Ozone dosages used in this investigation were 15,30 and $45 \mathrm{mg} / \mathrm{L}$ which corresponded to the ozone contact time of approximately 7.5, 17 and $27 \mathrm{~min}$, respectively. In general, higher molecular weight N-nitrosamines were more effectively removed by ozonation (Figure 2). For example, NDBA which has the highest molecular weight among the N-nitrosamines was removed by as much as $79 \%$. Increasing ozone dosage resulted in a linear reduction in the concentration of most N-nitrosamines (Figure 3). In contrast, low molecular weight aliphatic Nnitrosamines (i.e. NDMA, NMEA and NDEA) had a very low removal efficiency $(<23 \%)$. In particular, NMDA which has the lowest molecular weight among N-nitrosamines revealed less than $10 \%$ removal with the maximum ozone dosage applied (i.e. $45 \mathrm{mg} / \mathrm{L}$ ). At the highest ozone dosage of $45 \mathrm{mg} / \mathrm{L}$ used in this study, the transformation of NMOR was $36 \%$. Further

investigation revealed that $\mathrm{N}$-nitrosamine removal by ozonation was proportional $\left(\mathrm{R}^{2}=0.92\right)$ to the number of aliphatic carbon atoms in their chemical structure (Figure 4). A similar correlation 
has also been reported by Landsman et al. (2007) who studied the destruction of N-nitrosamines using hydroxyl radicals $(\cdot \mathrm{OH})$ formed from a combination of ultraviolet radiation and hydrogen peroxide. Because hydroxyl radicals can be formed by ozone decomposition in an aqueous solution at pH 7-8 (Elovitz et al. 2000) and hydroxyl radicals can transform N-nitrosamines, the transformation of $\mathrm{N}$-nitrosamines by ozonation in the synthetic solution may be caused by reactions with hydroxyl radicals. Hydroxyl radical reacts with N-nitrosamines and form methylene carbon-centred radical as shown in equation 2 (Landsman et al. 2007). These radicals decompose to variety of smaller compounds such as methylamine, dimethylamine, nitromethane and ammonium via several pathways (Lv et al. 2013). Landsman et al. (2007) suggested that these carbon-centred radicals are also subjective to a repair reaction as represented in equation 3. The repair reactions in larger $\mathrm{N}$-nitrosamines can be slower than those in smaller N-nitrosamines due to steric and resonance stabilization, which leads to a higher transformation efficiency in the larger N-nitrosamines (Landsman et al. 2007).

$[2] \quad \cdot \mathrm{OH}+\mathrm{R}_{1} \mathrm{R}_{2} \mathrm{~N}-\mathrm{NO} \quad \rightarrow \quad \mathrm{H}_{2} \mathrm{O}+\cdot \mathrm{R}_{1} \mathrm{R}_{2} \mathrm{~N}-\mathrm{NO}$

[3] $\cdot \mathrm{R}_{1} \mathrm{R}_{2} \mathrm{~N}-\mathrm{NO}+\cdot \mathrm{H} \quad \rightarrow \quad \mathrm{R}_{1} \mathrm{R}_{2} \mathrm{~N}-\mathrm{NO}$

To confirm that the other N-nitrosamines were not formed as a result of N-nitrosamine transformation, the formation of $\mathrm{N}$-nitrosamines during ozonation was investigated at an ozone dosage of $30 \mathrm{mg} / \mathrm{L}$. A synthetic solution that contained a single N-nitrosamine (i.e. NMOR or NDBA) was used. No formation of the other N-nitrosamines was identified during the ozonation of NMOR or NDBA (data not shown). The results reported here indicate that an oxidation of Nnitrosamines by ozonation transforms $\mathrm{N}$-nitrosamines without forming the other $\mathrm{N}$-nitrosamines 
as by-products or intermediates. Although it is beyond the scope of this study, the analysis of transformed N-nitrosamine intermediates will be useful to further understand the chemical transformation mechanism and ultimate fate of these molecules.

\section{[Figure 2]}

\section{[Figure 3]}

\section{[Figure 4]}

\section{[Table 2]}

\section{RO concentrate}

\section{Characteristics of the RO concentrate}

The analytical results (Table 2) revealed that organic and inorganic contents of the RO concentrate were about six to eight times higher than the RO feed. Similar values in RO concentrate can be found in a recent literature review by Pérez-González et al., (2012). Most Nnitrosamines were identified in the RO concentrate with the exceptions of NMEA, NPYR, and NPIP (Table 2). The absence of these three N-nitrosamines in the RO concentrate does not allow evaluating the effects of ozonation on a full set of N-nitrosamines. Thus, additional Nnitrosamines were introduced the RO concentrate to obtain approximately $250 \mathrm{ng} / \mathrm{L}$ of each Nnitrosamine concentration for further experiments. 


\section{Bulk organic matter removal by ozone treatment}

Ozone treatment could reduce colour (measured as $\mathrm{UV}_{400}$ absorbance), $\mathrm{UV}_{254}$ absorbance, and TOC concentration in the RO concentrate (Figure 5). Ozonation with a $15 \mathrm{mg} / \mathrm{L}$ ozone dosage resulted in as much as $60 \%$ reduction in $\mathrm{UV}_{400}$ absorbance (Figure 5a) which indicates that decolouring the RO concentrate can be achieved with a relatively small ozone dosage. The maximum ozone dosage used in this study (i.e. $45 \mathrm{mg} / \mathrm{L}$ ) led to an $82 \%$ reduction in $\mathrm{UV}_{400}$ absorbance. Ozonation was less effective to the reduction of $\mathrm{UV}_{254}$ absorbance. $\mathrm{UV}_{254}$ absorbance was proportionally reduced with increasing ozone dosage (Figure 5b). As a result, ozone dosage of $45 \mathrm{mg} / \mathrm{L}$ resulted in $60 \%$ reduction in $\mathrm{UV}_{254}$ absorbance. On the other hand, only a slight decrease in TOC concentration $(<10 \%)$ was observed (Figure $5 \mathrm{c})$. The results reported here indicate that organics in the RO concentrate can be degraded with ozonation, but complete mineralisation of organics may not occur.

\section{[Figure 5]}

\section{$\mathrm{N}$-nitrosamine removal by ozonation}

The ozone contact times to achieve the ozone dosage of 15,30 and $45 \mathrm{mg} / \mathrm{L}$ in the $\mathrm{RO}$ concentrate were approximately 6,12, 19 min, respectively. High molecular weight Nnitrosamines (i.e. NPIP, NMOR, NDPA and NDBA) in the RO concentrate were effectively transformed by ozonation (Figure 6). On the other hand, concentrations of low molecular weight N-nitrosamines (i.e. NDMA, NMEA, NPYR and NDEA) increased with an ozone dosage of 15$30 \mathrm{mg} / \mathrm{L}$ (Figure 6). In particular, NDEA revealed a considerable increase in concentration. The increased concentrations of these low molecular weight $\mathrm{N}$-nitrosamines indicate that the 
formation of $\mathrm{N}$-nitrosamines can occur as a result of ozone-induced oxidative processes in the RO concentrate. As described earlier, the formation of NDMA and NDEA observed here are unlikely to be from other N-nitrosamines or their intermediates. The concentrations of low molecular weight N-nitrosamines (i.e. NDMA, NMEA, NPYR and NDEA) decreased after reaching their maximum concentration with an ozone dosage of $15-30 \mathrm{mg} / \mathrm{L}$ (Figure 7). It is possible that when a lower ozone dosage (i.e. $15-30 \mathrm{mg} / \mathrm{L}$ ) was applied, the formation of these low molecular weight N-nitrosamines (i.e. NDMA, NMEA, NPYR and NDEA) may have exceeded their transformations, resulting in an increase in their concentration. After a majority of $\mathrm{N}$-nitrosamine precursors were transformed into N-nitrosamines by ozone oxidation, the transformation of these $\mathrm{N}$-nitrosamines may have then exceeded their formation, leading to the reduction in their concentrations at a $45 \mathrm{mg} / \mathrm{L}$ ozone dosage. However, there are two exceptions. The concentrations of NDMA and NDEA at the maximum ozone dosage (i.e. $45 \mathrm{mg} / \mathrm{L}$ ) were 14 and $38 \%$ higher than their initial concentrations, respectively.

The concentrations of high molecular weight N-nitrosamines (i.e. NPIP, NMOR, NDPA and NDBA) decreased during ozonation (Figure 7). This is consistent with our earlier observation that these high molecular weight $\mathrm{N}$-nitrosamines are more degradable by ozonation as demonstrated earlier in this study and their transformation rate are faster than their formation rates. The reactions between ozone, hydrogen radical, and organic substances in the RO concentrate are inherently complex and thus the formation and transformation of $\mathrm{N}$-nitrosamines cannot be readily separated. For example, natural organic matters and bicarbonate ions in natural water are known to be hydroxyl radical scavengers, and their concentrations considerably affect the NDMA oxidation rate (Lee et al. 2007). Nevertheless, the results reported here suggest that 
the balance between $\mathrm{N}$-nitrosamines formation and transformation by ozonation can be an important factor determining N-nitrosamine concentrations after ozonation.

\section{[Figure 6]}

\section{[Figure 7]}

\section{Conclusions}

Ozonation in the synthetic solution revealed a reduction in concentration of eight $\mathrm{N}$-nitrosamines selected in this study. The transformation of N-nitrosamines at the ozone dosage of $45 \mathrm{mg} / \mathrm{L}$ ranged from 7 to $79 \%$. The degree of N-nitrosamine removal by ozonation was strongly correlated with the number of aliphatic carbon atoms of $\mathrm{N}$-nitrosamines. Ozonation of RO concentrates could reduce the concentration of high molecular weight N-nitrosamines (i.e. NPIP, NMOR, NDPA and NDBA). However, the concentration of low molecular weight Nnitrosamines (i.e. NDMA, NMEA, NPYR and NDEA) increased with 15-30 mg/L ozone dosage and then decreased with further ozone dosage. Results reported here suggest that the balance between N-nitrosamine formation and transformation by ozonation is likely to be an important factor determining $\mathrm{N}$-nitrosamine concentrations in ozone treated $\mathrm{RO}$ concentrates.

\section{Acknowledgements}

The authors acknowledge the University of Wollongong for a $\mathrm{PhD}$ scholarship awarded to Takahiro Fujioka. 


\section{References}

Alborzfar, Maryam, Karine Escande, and Stephen J. Allen. 2000. "Removal of 3,4-dichlorobut1-ene using ozone oxidation." Water Research 34 (11):2963-2970.

Andrzejewski, Przemyslaw, Barbara Kasprzyk-Hordern, and Jacek Nawrocki. 2008. "Nnitrosodimethylamine (NDMA) formation during ozonation of dimethylamine-containing waters." Water Research 42 (4-5):863-870.

Andrzejewski, Przemyslaw, and Jacek Nawrocki. 2009. "N-nitrosodimethylamine (NDMA) as a product of potassium permanganate reaction with aqueous solutions of dimethylamine (DMA)." Water Research 43 (5):1219-1228.

Ang, Wui Seng, Ngai Yin Yip, Alberto Tiraferri, and Menachem Elimelech. 2011. "Chemical cleaning of RO membranes fouled by wastewater effluent: Achieving higher efficiency with dual-step cleaning." Journal of Membrane Science 382 (1-2):100-106.

Bellona, Christopher, Jörg E. Drewes, Pei Xu, and Gary Amy. 2004. "Factors affecting the rejection of organic solutes during NF/RO treatment - A literature review." Water Research 38 (12):2795-2809.

Benner, Jessica, Elisabeth Salhi, Thomas Ternes, and Urs von Gunten. 2008. "Ozonation of reverse osmosis concentrate: Kinetics and efficiency of beta blocker oxidation." Water Research 42 (12):3003-3012.

Bond, Tom, Jin Huang, Michael R. Templeton, and Nigel Graham. 2011. "Occurrence and control of nitrogenous disinfection by-products in drinking water - A review." Water Research 45 (15):4341-4354.

Elovitz, Michael S., Urs von Gunten, and Hans-Peter Kaiser. 2000. "Hydroxyl Radical/Ozone Ratios During Ozonation Processes. II. The Effect of Temperature, pH, Alkalinity, and DOM Properties." Ozone: Science \& Engineering 22 (2):123-150.

Farré, Maria José, Katrin Döderer, Laurence Hearn, Yvan Poussade, Jurg Keller, and Wolfgang Gernjak. 2011a. "Understanding the operational parameters affecting NDMA formation at Advanced Water Treatment Plants." Journal of Hazardous Materials 185 (2-3):15751581.

Farré, Maria José, Julien Reungoat, Francois Xavier Argaud, Maxime Rattier, Jürg Keller, and Wolfgang Gernjak. 2011b. "Fate of N-nitrosodimethylamine, trihalomethane and haloacetic acid precursors in tertiary treatment including biofiltration." Water Research 45 (17):5695-5704.

Fujioka, Takahiro, Stuart J. Khan, James A. McDonald, Rita K. Henderson, Yvan Poussade, Jörg E. Drewes, and Long D. Nghiem. 2013a. "Effects of membrane fouling on N-nitrosamine 
rejection by nanofiltration and reverse osmosis membranes." Journal of Membrane Science 427 (0):311-319.

Fujioka, Takahiro, Stuart J. Khan, James A. McDonald, Annalie Roux, Yvan Poussade, Jörg E. Drewes, and Long D. Nghiem. 2013b. "N-nitrosamine rejection by reverse osmosis membranes: A full-scale study." Water Research 47 (16):6141-6148.

Fujioka, Takahiro, Stuart J. Khan, Yvan Poussade, Jörg E. Drewes, and Long D. Nghiem. 2012. "N-nitrosamine removal by reverse osmosis for indirect potable water reuse - A critical review based on observations from laboratory-, pilot- and full-scale studies." Separation and Purification Technology 98 (0):503-515.

Jermann, Doris, Wouter Pronk, Markus Boller, and Andrea I. Schäfer. 2009. "The role of NOM fouling for the retention of estradiol and ibuprofen during ultrafiltration." Journal of Membrane Science 329 (1-2):75-84.

Krasner, Stuart W., Paul Westerhoff, Baiyang Chen, Bruce E. Rittmann, and Gary Amy. 2009. "Occurrence of disinfection byproducts in United States wastewater treatment plant effluents." Environmental Science \& Technology 43 (21):8320-8325.

Krauss, Martin, Philipp Longrée, Emmanuel van Houtte, Johan Cauwenberghs, and Juliane Hollender. 2010. "Assessing the fate of Nitrosamine precursors in wastewater treatment by physicochemical fractionation." Environmental Science \& Technology 44 (20):78717877.

Landsman, Nicholas A., Katy L. Swancutt, Christine N. Bradford, Casandra R. Cox, James J. Kiddle, and Stephen P. Mezyk. 2007. "Free Radical Chemistry of Advanced Oxidation Process Removal of Nitrosamines in Water." Environmental Science \& Technology 41 (16):5818-5823.

Lee, Carson O., Kerry J. Howe, and Bruce M. Thomson. 2012. "Ozone and biofiltration as an alternative to reverse osmosis for removing PPCPs and micropollutants from treated wastewater." Water Research 46 (4):1005-1014.

Lee, Changha, Jeyong Yoon, and Urs Von Gunten. 2007. "Oxidative degradation of Nnitrosodimethylamine by conventional ozonation and the advanced oxidation process ozone/hydrogen peroxide." Water Research 41 (3):581-590.

Lv, Juan, Yongmei Li, and Yun Song. 2013. "Reinvestigation on the ozonation of Nnitrosodimethylamine: Influencing factors and degradation mechanism." Water Research 47 (14):4993-5002.

McDonald, James A., Nick B. Harden, Long D. Nghiem, and Stuart J. Khan. 2012. "Analysis of $\mathrm{N}$-nitrosamines in water by isotope dilution gas chromatography-electron ionisation tandem mass spectrometry." Talanta 99:146-152. 
Mitch, William A., Jonathan O. Sharp, R. Rhodes Trussell, Richard L. Valentine, Lisa AlvarezCohen, and David L. Sedlak. 2003. "N-Nitrosodimethylamine (NDMA) as a drinking water contaminant: A review." Environmental Engineering Science 20 (5):389-404.

Pérez-González, A., A. M. Urtiaga, R. Ibáñez, and I. Ortiz. 2012. "State of the art and review on the treatment technologies of water reverse osmosis concentrates." Water Research 46 (2):267-283.

Pisarenko, Aleksey N., Benjamin D. Stanford, Dongxu Yan, Daniel Gerrity, and Shane A. Snyder. 2012. "Effects of ozone and ozone/peroxide on trace organic contaminants and NDMA in drinking water and water reuse applications." Water Research 46 (2):316-326.

Plumlee, Megan H., Montserrat López-Mesas, Andy Heidlberger, Kenneth P. Ishida, and Martin Reinhard. 2008. "N-nitrosodimethylamine (NDMA) removal by reverse osmosis and UV treatment and analysis via LC-MS/MS." Water Research 42 (1-2):347-355.

Rakness, Kerwin, Gilbert Gordon, Bruno Langlais, Willy Masschelein, Nobuo Matsumoto, Yves Richard, C. Michael Robson, and Isao Somiya. 1996. "Guideline for Measurement of Ozone Concentration in the Process Gas From an Ozone Generator." Ozone: Science \& Engineering 18 (3):209-229.

Reungoat, J., M. Macova, B. I. Escher, S. Carswell, J. F. Mueller, and J. Keller. 2010. "Removal of micropollutants and reduction of biological activity in a full scale reclamation plant using ozonation and activated carbon filtration." Water Research 44 (2):625-637.

Reyes-Contreras, Carolina, Carmen Domínguez, and Josep M. Bayona. 2012. "Determination of nitrosamines and caffeine metabolites in wastewaters using gas chromatography mass spectrometry and ionic liquid stationary phases." Journal of Chromatography A 1261 (0):164-170.

Schmidt, Carsten K., and Heinz-Jürgen Brauch. 2008. "N,N-Dimethylsulfamide as precursor for N-Nitrosodimethylamine (NDMA) formation upon ozonation and its fate during drinking water treatment." Environmental Science \& Technology 42 (17):6340-6346.

Shannon, Mark A., Paul W. Bohn, Menachem Elimelech, John G. Georgiadis, Benito J. Marinas, and Anne M. Mayes. 2008. "Science and technology for water purification in the coming decades." Nature 452 (7185):301-310.

Snyder, Shane A., Eric C. Wert, David J. Rexing, Ronald E. Zegers, and Douglas D. Drury. 2006. "Ozone Oxidation of Endocrine Disruptors and Pharmaceuticals in Surface Water and Wastewater." Ozone: Science \& Engineering 28 (6):445-460.

USEPA. 1993. "N-Nitrosodimethylamine (CASRN 62-75-9) - Integrated risk information system (IRIS)." http://www.epa.gov/iris/subst/0045.htm. 
Table 1. Selected N-nitrosamines and their molecular mass.

\begin{tabular}{|c|c|c|c|}
\hline Compound & Structure & $\begin{array}{l}\text { Empirical } \\
\text { formula }\end{array}$ & $\begin{array}{l}\text { Molecular } \\
\text { mass } \\
(\mathrm{g} / \mathrm{mol})\end{array}$ \\
\hline NDMA & & $\mathrm{C}_{2} \mathrm{H}_{6} \mathrm{~N}_{2} \mathrm{O}$ & 74.05 \\
\hline NMEA & & $\mathrm{C}_{3} \mathrm{H}_{8} \mathrm{~N}_{2} \mathrm{O}$ & 88.06 \\
\hline NPYR & & $\mathrm{C}_{4} \mathrm{H}_{8} \mathrm{~N}_{2} \mathrm{O}$ & 100.06 \\
\hline NDEA & & $\mathrm{C}_{4} \mathrm{H}_{10} \mathrm{~N}_{2} \mathrm{O}$ & 102.08 \\
\hline NPIP & & $\mathrm{C}_{5} \mathrm{H}_{10} \mathrm{~N}_{2} \mathrm{O}$ & 114.08 \\
\hline NMOR & & $\mathrm{C}_{4} \mathrm{H}_{8} \mathrm{~N}_{2} \mathrm{O}_{2}$ & 116.06 \\
\hline NDPA & & $\mathrm{C}_{6} \mathrm{H}_{14} \mathrm{~N}_{2} \mathrm{O}$ & 130.11 \\
\hline NDBA & & $\mathrm{C}_{8} \mathrm{H}_{18} \mathrm{~N}_{2} \mathrm{O}$ & 158.14 \\
\hline
\end{tabular}


Table 2. General water quality and ambient N-nitrosamine concentrations in the RO feed and RO concentrate samples.

\begin{tabular}{lll}
\hline Parameter & RO feed & RO concentrate \\
\hline Conductivity [mS/cm] & 1.0 & 5.5 \\
$\mathrm{pH}[-]$ & 7.0 & 7.8 \\
$\mathrm{TOC}[\mathrm{mg} / \mathrm{L}]$ & 21 & 117 \\
$\mathrm{Na}^{+}[\mathrm{mg} / \mathrm{L}]$ & 118 & 875 \\
$\mathrm{Mg}^{2+}[\mathrm{mg} / \mathrm{L}]$ & 12 & 94 \\
$\mathrm{~K}^{+}[\mathrm{mg} / \mathrm{L}]$ & 20 & 149 \\
$\mathrm{Ca}^{2+}[\mathrm{mg} / \mathrm{L}]$ & 33 & 253 \\
$\mathrm{Cl}^{-}[\mathrm{mg} / \mathrm{L}]$ & 132 & 1,150 \\
$\mathrm{NO}_{3}^{-}[\mathrm{mg} / \mathrm{L}]$ & 37 & 298 \\
$\mathrm{SO}_{4}{ }^{2-}[\mathrm{mg} / \mathrm{L}]$ & 30 & 273 \\
\hline $\mathrm{NDMA}[\mathrm{ng} / \mathrm{L}]$ & 6.7 & 26 \\
$\mathrm{NMEA}[\mathrm{ng} / \mathrm{L}]$ & $\mathrm{n} . \mathrm{q}$. & $\mathrm{n} . \mathrm{q}$. \\
$\mathrm{NPYR}[\mathrm{ng} / \mathrm{L}]$ & n.q. & n.q. \\
NDEA [ng/L] & 7.4 & 17 \\
NPIP [ng/L] & n.q. & n.q. \\
NMOR [ng/L] & 177 & 1013 \\
NDPA [ng/L] & n.q. & 5.4 \\
NDBA [ng/L] & n.q. & 8.0 \\
\hline
\end{tabular}

n.q., not quantifiable. 


\section{LIST OF FIGURES}

Figure 1. Schematic diagram of ozonation apparatus.

Figure 2. Effects of ozonation on N-nitrosamine concentration in the synthetic solution (20 $\mathrm{mM} \mathrm{NaCl}, 1 \mathrm{mM} \mathrm{NaHCO}{ }_{3}, 1 \mathrm{mM} \mathrm{CaCl}_{2}, \mathrm{pH} 8.0 \pm 0.1$, solution temperature $28^{\circ} \mathrm{C}$ ). Values reported here is the average of duplicate results. Ozone dosages (15, 30 and $45 \mathrm{mg} / \mathrm{L})$ corresponded to the ozone contact time of approximately 7.5, 17, and $27 \mathrm{~min}$, respectively.

Figure 3. Effects of ozone dosage on N-nitrosamine concentration in the synthetic solution. Experimental conditions are described in Figure 2.

Figure 4. Effects of ozonation on N-nitrosamine concentration in the synthetic solution as a function of the number of aliphatic carbon atoms of N-nitrosamines (ozone dosage $=45$ $\mathrm{mg} / \mathrm{L}$ ). Experimental conditions are described in Figure 2.

Figure 5. Effects of ozonation on the removal of (a) relative colour ( $\mathrm{UV}_{400}$ absorbance), (b) $\mathrm{UV}_{254}$ absorbance, and (c) TOC in the RO concentrate (pH $7.8 \pm 0.1$, solution temperature $\left.28{ }^{\circ} \mathrm{C}\right)$.

Figure 6. Effects of ozonation on N-nitrosamines in the RO concentrate $(\mathrm{pH} 7.8 \pm 0.1$, solution temperature $\left.28{ }^{\circ} \mathrm{C}\right)$. Ozone dosages (15, 30 and $\left.45 \mathrm{mg} / \mathrm{L}\right)$ corresponded to the ozone contact time of approximately 6, 12, and 19 min, respectively.

Figure 7. Effects of ozone dosage on N-nitrosamines in the RO concentrate $(\mathrm{pH} 7.8 \pm 0.1$, solution temperature $28^{\circ} \mathrm{C}$ ). 


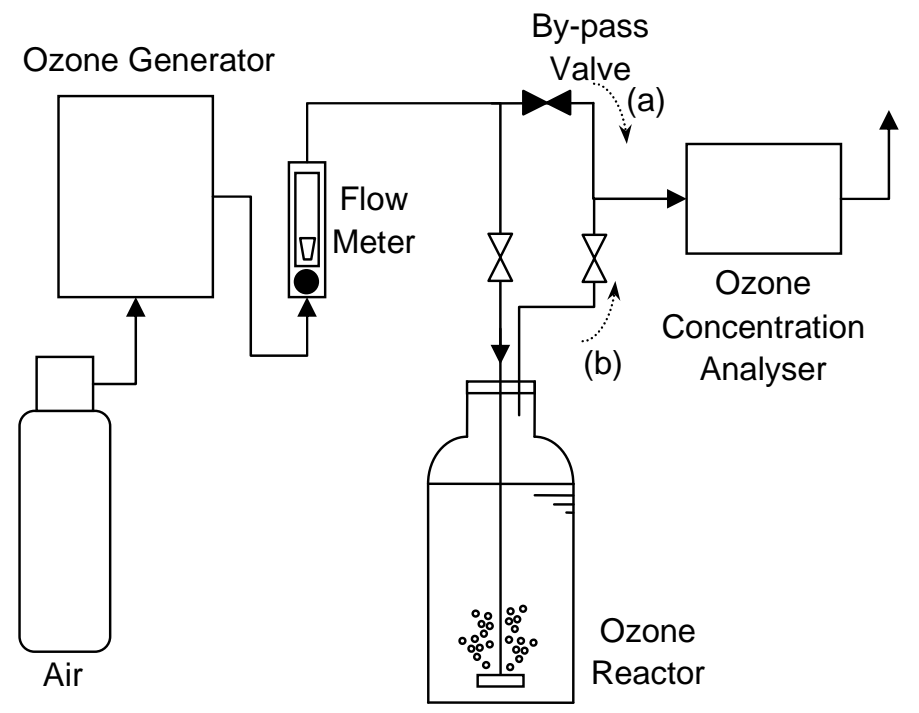

Figure 1 


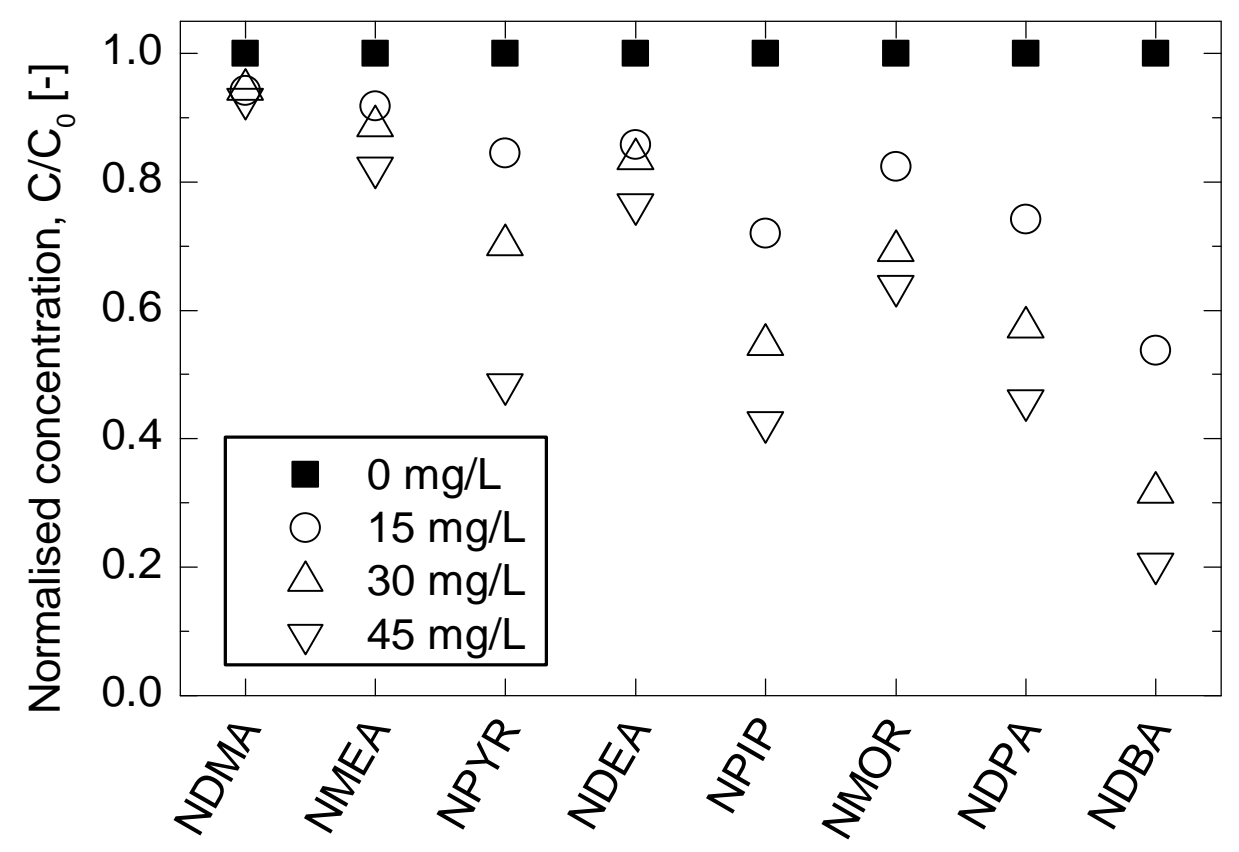

Figure 2 


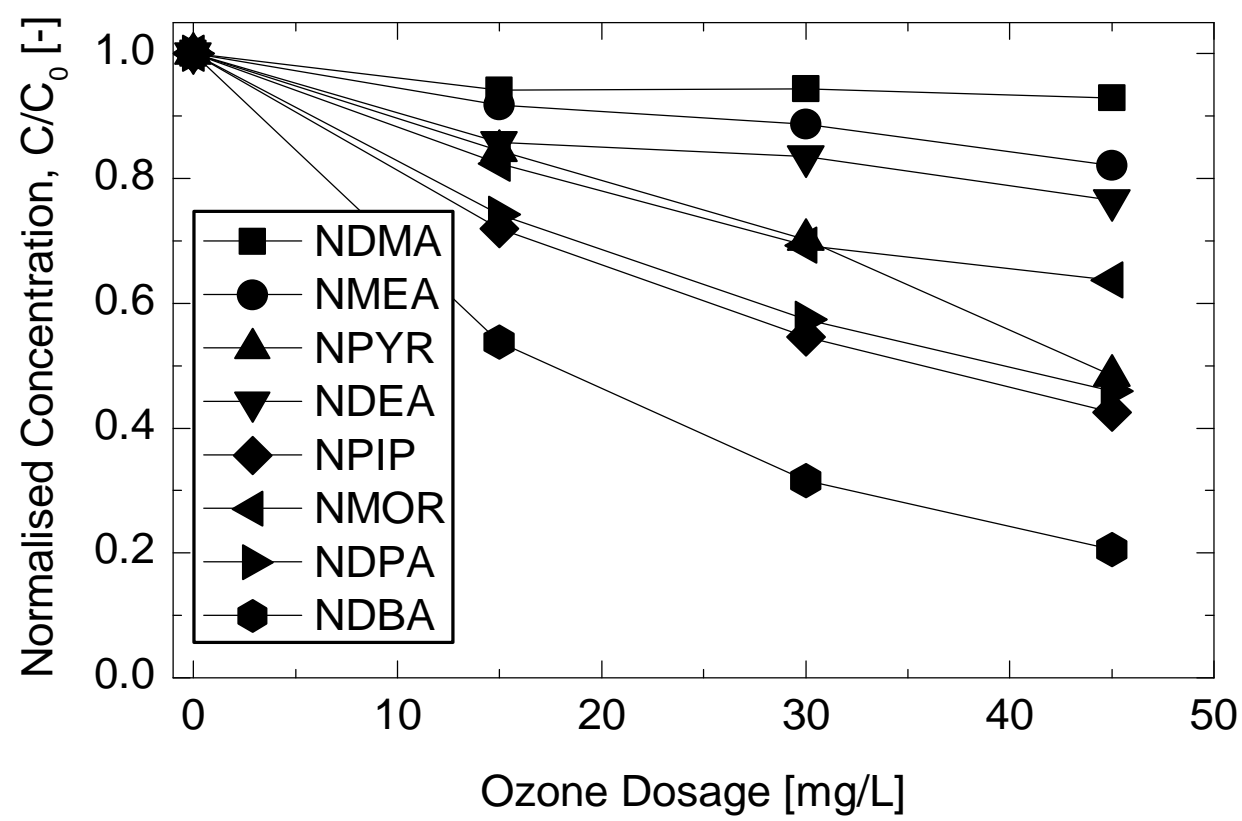

Figure 3 


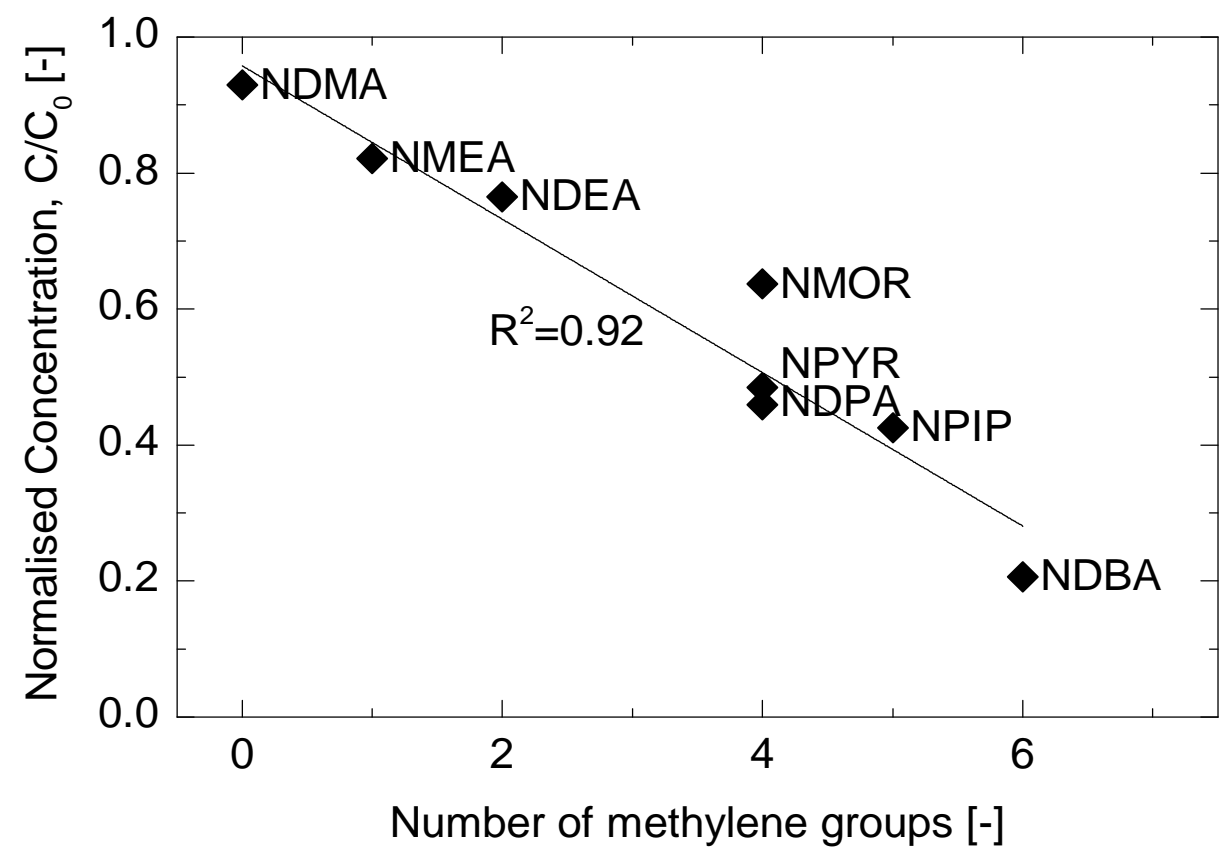

Figure 4 

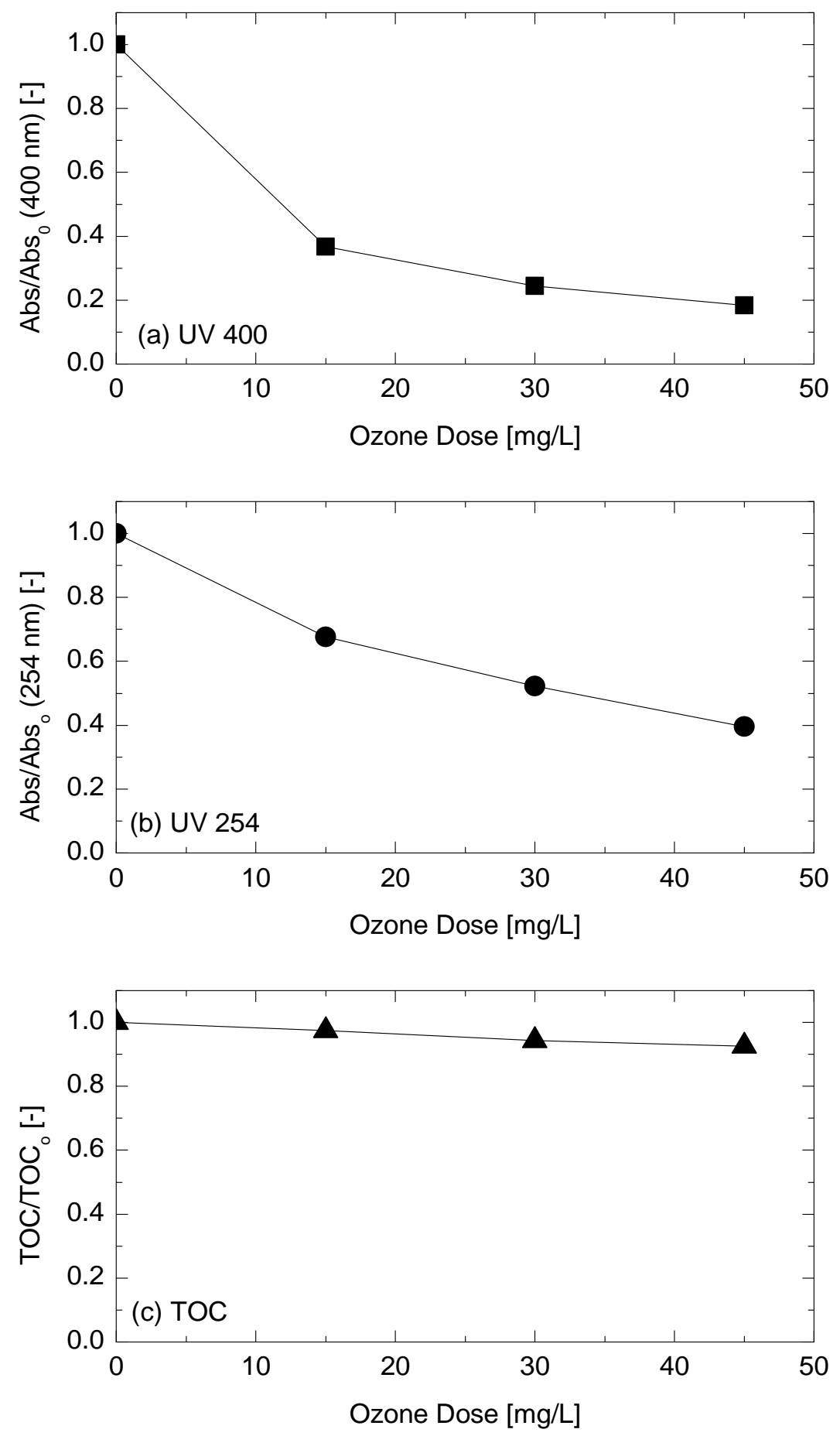

Figure 5 


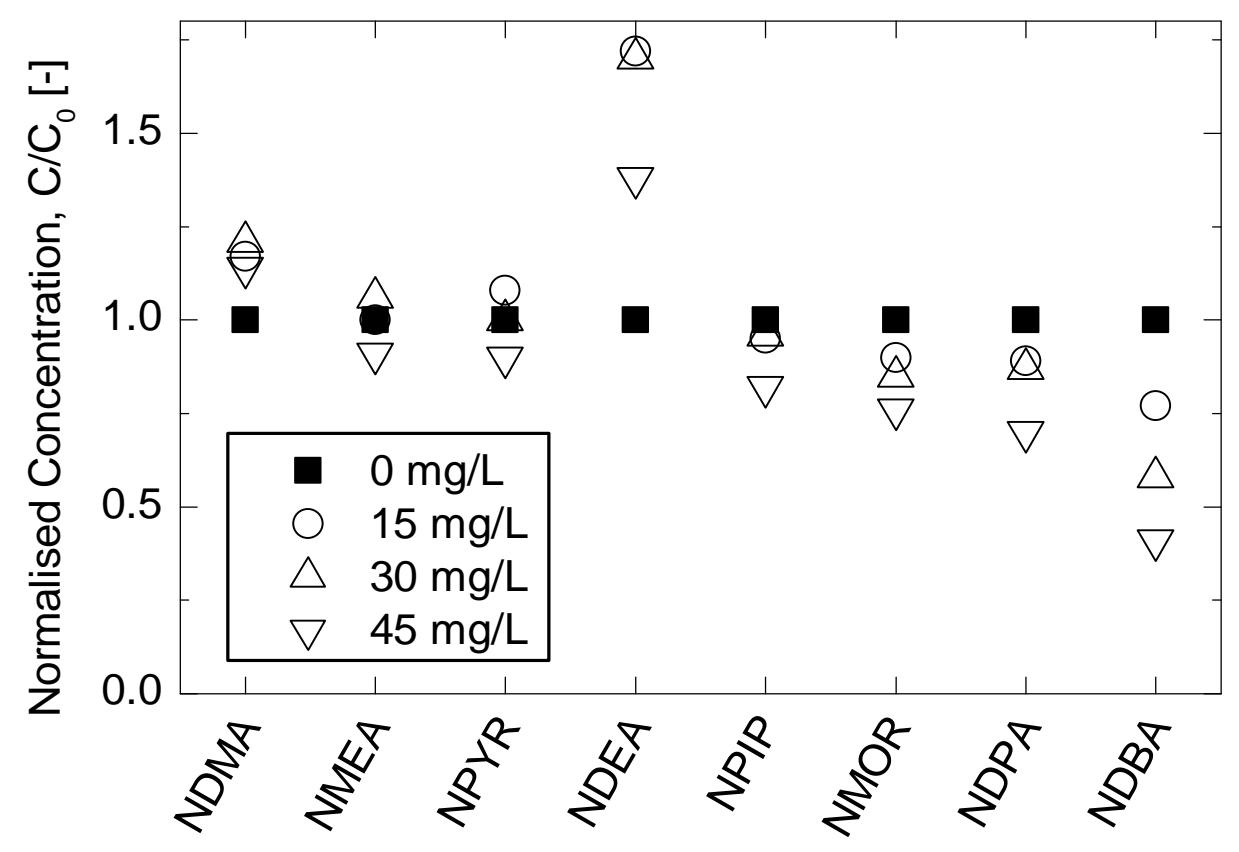

Figure 6 


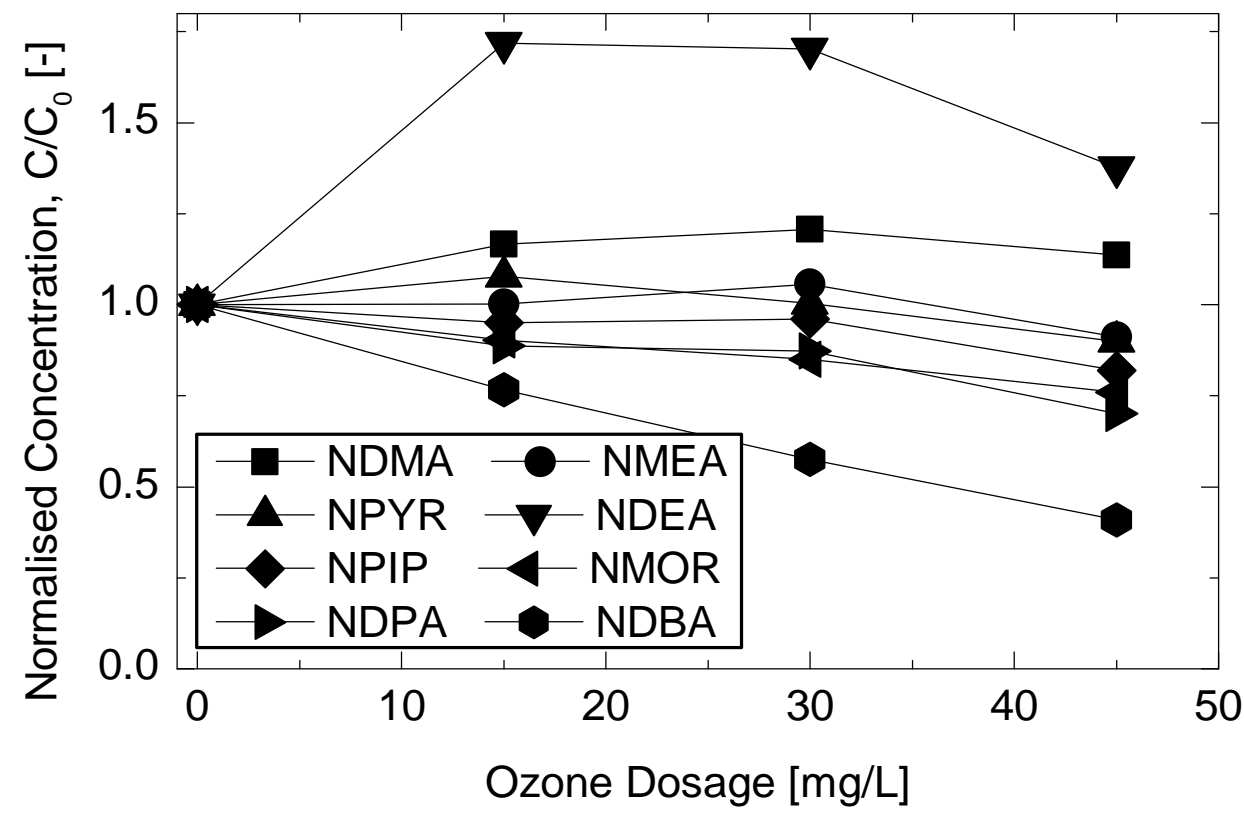

Figure 7 